investigar por que e como as coleções modernas foram formadas. Assim, The origins of museums fez renascer, a partir de nova perspectiva, os estudos sobre as coleções e o colecionismo dos séculos XVI a XVIII. Desta conferência resultou uma coletânea de mesmo nome e o lançamento daquele que é hoje um dos mais importantes periódicos da área, o Journal of the History of Collections. De lá para cá, estudiosos das áreas de história, história da arte, antropologia e estudos culturais, entre outros, vêm explorando as múltiplas faces, origens e consequências do colecionismo.

A recém-lançada coletânea organizada por Daniela Bleichmar e Peter Mancall - Collecting across cultures apresenta-se como sucessora de The origins of museums. Na apresentação do livro, Malcom Baker afirma que, se o trabalho pioneiro de 1985 reestabeleceu o senso de totalidade das coleções, com o presente livro dar-se-ia um passo adiante enfocando a circulação global dos objetos. A comparação é indevida, se não por outras razões, simplesmente por conta da escala da mudança que aquele livro provocou - evidentemente, ainda não sabemos os seus efeitos. Mas há uma série de contribuições e inovações em Collecting across cultures que certamente irão interessar os especialistas e poderão

BLEICHMAR, Daniela \& MANCALL, Peter. 2011. Collecting across cultures. Material exchanges in the Early Modern Atlantic World. Philadelphia: University of Pennsylvania Press. 361 pp.

\section{Mariana Françozo}

Faculdade de Arqueologia, Universidade de Leiden, Holanda

Há quase 30 anos, em 1985, uma conferência organizada em Oxford por Oliver Impey e Arthur McGregor propôs-se a inspirar novas linhas de trabalho. Neste sentido, aliás, vale lembrar que o presente livro é também resultado de uma conferência internacional, esta organizada na Huntington Library, Califórnia. Aparentemente, nem todas as apresentações transformaram-se em capítulos - o que é uma pena pois, a julgar por seus títulos, algumas das que ficaram de fora parecem ter lidado justamente com um dos temas mais atuais e instigantes deste campo de estudos: as coleções não europeias e as práticas não ocidentais de colecionar e classificar. Talvez reflexo de uma área 
de estudos que se inicia, o tema é levantado apenas na introdução e em alguns capítulos da coletânea.

Dividida em quatro segmentos, a coletânea é aberta com o tema da construção do conhecimento no período moderno. Daniela Bleichmar traz uma contribuição original ao analisar as coleções modernas como espaços sociais narrados. As escolhas e os significados por trás dos modos de exibir e apresentar uma coleção são temas centrais do debate atual no mundo dos museus; a autora, porém, leva-os de volta ao século XVII através do estudo de inventários e catálogos. Em um artigo de grande erudição, Benjamin Schmidt aborda coleções através de um olhar transcultural, estudando o movimento global de um objeto e sua representação visual: o parassol. Schmidt nos lembra que o colecionismo moderno tomou diversas formas materiais (objetos, inscrições, imagens, descrições textuais), e assim criou "ícones performativos" (:34) que circulavam e tinham seus significados transformados. Propõe, portanto, que pensemos na representação do exótico como uma viagem iconográfica sem ponto de partida ou chegada.

Alain Schnapp estuda o lugar dos povos indígenas americanos num contexto global de produção do conhecimento. $\mathrm{Na}$ falta de vestígios arqueológicos como os presentes no sul da Europa, os humanistas do Norte europeu usaram as civilizações e os povos americanos como forma de entender seu próprio passado, construindo uma história comparativa das culturas e das raças. Schnapp, porém, vai além de uma história da etnologia na Europa e volta seu olhar para as elites indígenas do México dos séculos XVI e XVII que, escolarizadas num contexto colonial, passaram a criar também formas próprias de conhecimento. Temos aqui o primeiro exemplo, nesta coletânea, do colecionismo visto de outro lado.
A segunda parte da coletânea, sobre colecionismo e formação de networks globais, inicia-se com um brilhante artigo de Carina Johnson sobre a circulação e a transformação de objetos astecas no império Habsburgo. Partindo de um episódio aparentemente sem sentido a ordem dada por Carlos V, em 1535, para derreter parte dos objetos astecas em ouro e prata que ele havia recebido como presente de Hernan Cortés há apenas 15 anos - a autora explora a recepção, a circulação e a posterior liquidação do tesouro asteca para mostrar como a Reforma Protestante transformou os símbolos da soberania Habsburgo, transformando também a forma material das coleções reais.

Continuando o tema das coleções espanholas, no capítulo seguinte, José Marcaida e Juan Pimentel enfocam a pintura de natureza-morta na Espanha da Era do Ouro. Analisam a conexão íntima entre a cultura barroca e a revolução científica no contexto de um período que em que a pintura - uma coleção de arte - triunfou sobre outras formas de colecionar. Os autores defendem que a natureza-morta colocava objetos mundanos no centro da atenção, uma abordagem inovadora da natureza como parte de uma cultura visual em desenvolvimento. Na sequência, Robert Batchelor parte do episódio, em 1641, em que um comerciante javanês assassinou mercadores ingleses com a mesma faca cerimonial que há pouco havia tentado lhes vender. Explorando a ligação entre comércio global e colecionismo no caso do Sudeste asiático, Batchelor discute como a emergência do que hoje se chama "mundo atlântico" foi resultante de um emaranhado de experiências de todos os tipos-econômicas, diplomáticas, simbólicas - em outros cantos do planeta. E, ao fazê-lo, demonstra a inadequação do subtítulo desta coletânea: as redes atlânticas estavam de fato ligadas a um 
movimento de pessoas, mercadorias e relações em escala global.

Cecile Fromont trata de um conjunto de manuscritos ilustrados, compostos por frades capuchinhos entre 1650-1750, em que diferentes povos do Reino do Congo e Angola são descritos e caracterizados. Empreendendo uma bela e detalhada análise do conteúdo visual dos documentos - manuscritos didáticos - a autora esclarece como os capuchinhos, enquanto membros de uma ordem mendicante, não podiam colecionar objetos - mas compunham descrições visuais que, uma vez levadas à Europa, serviriam como um compêndio informativo para os futuros missionários. Ao optar pela análise unicamente visual dos códices, a autora deixa ao leitor a curiosidade sobre a posterior recepção deste material na Europa.

Em seguida, Sarah Benson traz uma das contribuições mais instigantes da coletânea. Partindo da presença de diplomatas do Sião na França em finais do século XVI, a autora faz uma verdadeira antropologia dos modos de ver, observar e colecionar naquele país, mostrando claramente como o colecionismo não era uma prática apenas ocidental. Apesar da escassez de fontes que iluminem o lado asiático desta história, a autora consegue reconstruir, ainda que parcialmente, o conteúdo da coleção do Rei do Sião - instrumentos científicos europeus e notas e descrições da vida na corte francesa daquele período. $\mathrm{O}$ artigo aponta como o contexto que propiciou a expansão das coleções na Europa também provocou um crescente interesse pelos povos ocidentais como curiosidade: os europeus tornaram-se exóticos.

$\mathrm{Na}$ terceira parte, chega-se ao controverso tema da coleção de pessoas. Trevor Burnard aborda a escravidão na Jamaica, iniciando pela constatação de que, via de regra, escravos e escravidão raramente apareceram como tema de coleções. Contudo, ao explorar os diários e as notas do colecionador inglês Thomas Thistlewood, demonstra como os escravos configuravam uma coleção em si: vistos como mercadorias, apareciam listados em documentos legais assim como objetos em um inventário. O artigo aponta uma série de questões sobre a dificuldade prática e sobretudo moral, ainda existente, de "musealizar" a escravidão e tratar de uma coleção de pessoas. Da mesma forma, Peter Mancall explora a ideia de uma coleção de corpos ao discutir as diferentes atitudes ocidentais perante povos nativos americanos. O autor parte da exibição de indígenas em carne e osso nos séculos XVI e XVII e chega até as coleções de restos humanos dos séculos posteriores. Na medida em que reconstrói uma história de cinco séculos de atitudes europeias quanto aos corpos indígenas, o autor indica os desafios atuais para os museus herdeiros de tais coleções.

Finalmente, a quarta e última parte da coletânea debruça-se sobre as coleções europeias de objetos americanos nos séculos XVIII e XIX. Paz Cabello Carro apresenta uma descrição detalhada e minuciosa das coleções arqueológicas, etnográficas e naturalistas formadas em expedições espanholas à América Central e do Sul no século XVIII. Ao mesmo tempo, identifica os objetos então coletados que ainda existem em museus espanhóis na atualidade. O capítulo associa-se à contribuição seguinte, de Lisa Trever e Joanne Pillsbury, sobre a coleção do bispo Baltasar Martinez Companon (1737-1797), dono da maior e mais bem documentada coleção de história natural e objetos pré-colombianos do Peru setecentista. As autoras indicam a presença de saberes indígenas e locais na coleção de ilustrações de história natural de Companon; ao mesmo tempo, revelam que a prática colecionista existia na região andina ainda antes da chegada dos europeus. 
Já Pascal Riviale nos remete ao início do século XIX, momento em que a antropologia e a arqueologia tiveram um tremendo desenvolvimento impulsionado pela abertura das Américas às expedições científicas estrangeiras. Por um lado, soa um pouco fora de lugar afirmar a singularidade do século XIX como época de impacto para o colecionismo, as viagens exploratórias e as ciências europeias após 12 capítulos que demonstraram a amplitude e a relevância dessas mesmas atividades nos três séculos precedentes. Porém, é verdade que a abertura dos países americanos permitiu o reposicionamento do continente na agenda científica europeia. O autor comprova, assim, o quanto as coleções montadas nos oitocentos contribuíram para uma imagem inventada destes países. Um pouco no mesmo sentido, no último capítulo, Megan O'Neil analisa os álbuns elaborados por dois viajantes franceses no México, no século XIX, contendo imagens de mexicanos e anotações pessoais de seus autores sobre as experiências vividas. A autora usa este material para explorar as divergências entre modelos de representação e experiências coletivas e pessoais. Conclui, um pouco melancolicamente, que os padrões visuais representados nos dois álbuns continuam a ser, ainda hoje, as representações típicas feitas por um viajante estrangeiro no México.

De maneira geral, e apesar de certa falta de balanço entre os capítulos, Collecting across cultures alcança seu objetivo ao retratar o colecionismo como um fenômeno diverso e transcultural, intimamente relacionado ao comércio global no período moderno. Sem dúvida, representa uma evolução dos estudos sobre coleções nos últimos 30 anos. Sua maior contribuição, porém, é sugerir novos temas de pesquisa cujo desenvolvimento fará concretizar o salto qualitativo para além de The origins of museums: em primeiro lugar, é preciso encontrar as coleções e os colecionadores não ocidentais e, assim, trazer outras formas de conhecimento e outros sistemas classificatórios para o mesmo nível das coleções e da ciência ocidental; em segundo, empreender uma abordagem expandida da história atlântica que permita identificar e analisar as conexões índicas e pacíficas de um período marcado por relações verdadeiramente globais. 